\title{
Lack of Clinically Significant Improvement of Patients with Tardive Dyskinesia Following Phosphatidylcholine Therapy
}

\author{
Edward F. Domino, Wolfgang W. May, Sandra Demetriou, \\ Benjamin Mathews, Sandi Tait, and Beverly Kovacic
}

A double-blind controlled study was undertaken to examine the value of phosphatidylcholine as a treatment for tardive dyskinesia (TD) in 19 psychiatric patients. All patients were maintained on their usual psychotropic medication throughout the entire study. In addition, they were given either phosphatidylcholine $(30 \mathrm{~g} /$ day) or placebo for 6 weeks. Thirteen of the patients received the crossover treatment for 6 weeks, after which 10 of the 13 were continued on the crossover medication for an additional 6 weeks. At the end of the study, 5 patients had received phosphatidylcholine for 12 weeks and another 12 patients had received the drug for only 6 weeks. Plasma and red blood cell choline levels were monitored every 3 weeks as a measure of compliance. Although some patients showed clinical improvement of their $T D$, the results did not differ significantly between active drug and placebo. This was in spite of a marked elevation of plasma and red blood cell choline (up to $300 \%$ for the Lafayette Clinic patients and up to $400 \%$ for the patients from the Ypsilanti Regional Psychiatric Hospital) during treatment with phosphatidylcholine. Side effects of the drug included occasional gastrointestinal upsets and diarrhea but, in general, the medication was tolerated very well. The results indicate that large doses of phosphatidylcholine of soya origin are of no clinical value in treating symptoms of TD in spite of very large increases in blood choline.

\section{Introduction}

The report by Hirsch and Wurtman (1978) that dietary lecithin (phosphatidylcholine) can elevate brain levels of acetylcholine (ACh) prompted a number of investigators (see reviews by Jeste and Wyatt 1982a,b; Alphs and Davis 1983), including the authors, to assess lecithin as a treatment for tardive dyskinesia (TD). The rationale behind such treatment is based on evidence that TD is characterized by a relative functional deficit of striatal cholinergic activity (Klawans 1973). Choline released from the lecithin molecule might serve as a precursor for brain $\mathrm{ACh}$ and restore central cholinergic activity.

\footnotetext{
Supported by a grant from the Michigan Department of Mental Health and the Psychopharmacology Research Fund (E.F.D.). From the University of Michigan, Ann Arbor (E.F.D.), the Ypsilanti Regional Psychiatric Hospital, Ypsilanti, MI (W.W.M.), and the Lafayette Clinic, Detroit, MI (S.D., B.M., S.T., B.K.).

Address reprint requests to Dr. E.F. Domino, Department of Pharmacology, M6414 Medical Science Bldg. I, University of Michigan, Ann Arbor, MI 48109-0010.

Received April 17, 1985; revised June 18, 1985.
} 
Open studies on the use of lecithin as a treatment for TD tend to report favorable results (Alphs and Davis 1983). Blind studies (Table 1) have produced variable results.

The present report is of a blind, placebo-controlled study on the treatment of TD with a relatively pure form of lecithin ( $94 \%$ phosphatidylcholine) for a reasonable period of time (6 or 12 weeks).

\section{Methods}

Nineteen male or female patients with a diagnosis of TD were recruited from the southeastern area of Michigan for study as either inpatients or outpatients at the Lafayette Clinic (LC) or as inpatients at Ypsilanti Regional Psychiatric Hospital (Ypsi). Approval to conduct the study was obtained from the institutional review boards of LC and Ypsi. A diagnosis of TD was established by at least one neurologist and one psychiatrist. A patient was included in the study only if all of the physicians involved with the patient agreed that he or she had TD and only if the patient's informed consent was obtained. Psychiatric diagnoses were: 15 patients with schizophrenia, 2 with bipolar affective illness, 1 with senile dementia, and 1 with presenile dementia. All patients were maintained on their usual psychotropic medications throughout the entire study. Ages of the patients at the $L C$ ranged from 30 to 66, with an average of 60 years; at Ypsi they ranged from 46 to 84 , with an average of 67 years. Thus, the latter were somewhat older and all were inpatients. However, severity of the TD was similar between the two hospital groups of patients.

Phosphatidylcholine was administered in the form of Phospholipon 100 (American Lecithin Co., Atlanta, GA), which contains $94 \%$ phosphatidylcholine. The drug was dissolved in $0.9 \% \mathrm{NaCl}$, forming a solution that looks like evaporated milk. Placebo solution consisted of evaporated milk plus malt. Drug or placebo solution was dispensed to hospital staff or to outpatients who then used it in simple recipes calling for major ingredients of either cold milk, ice cream, sherbet, or frozen yogurt.

Rating scales employed were adapted from the "Early Clinical Drug Evaluation Unit Assessment Manual" (Guy 1976) and were as follows: Abnormal Involuntary Movement Scale (AIMS), Physician's Global Impression of Patient's Mental Illness, Nurse's Global Impression of Patient's Mental Illness, and the Emergent Symptom Scale (ESS). The rating scales were scored on the basis of live contact with the patient. Interrater reliability varied from 0.7 to 0.9 with a mean of about 0.8 . Subsequently, at scheduled times, videotapes of the patients were obtained under standardized conditions for later counting of abnormal movements by a single trained technician who was unaware of the current treatments. The videotapes were presented to him in a randomized order within and across patients.

Plasma and red blood cell choline were measured by gas chromatography-nitrogen phosphorus detection after chemical demethylation (Kosh et al. 1979; Jenden et al. 1968). Trimethylaminopropanol was used as the internal standard (Buchanan et al. 1980).

All patients were treated for 6 weeks with either phosphatidylcholine $(30 \mathrm{~g} / \mathrm{day})$ or placebo. Three patients at LC were given the crossover treatment for 6 weeks. All 10 of the Ypsi patients were given the crossover treatment for 12 weeks. At the end of the study, out of the total of 19 patients, 5 had received phosphatidylcholine for 12 weeks (at Ypsi) and another 12 patients had received the drug for only 6 weeks (5 at Ypsi and 7 at LC). A battery of data was obtained 1-3 times before each treatment and once after the 3rd, 6th, and, where applicable, the 12th week of treatment. A 1-3-month washout period was allowed between treatments. 


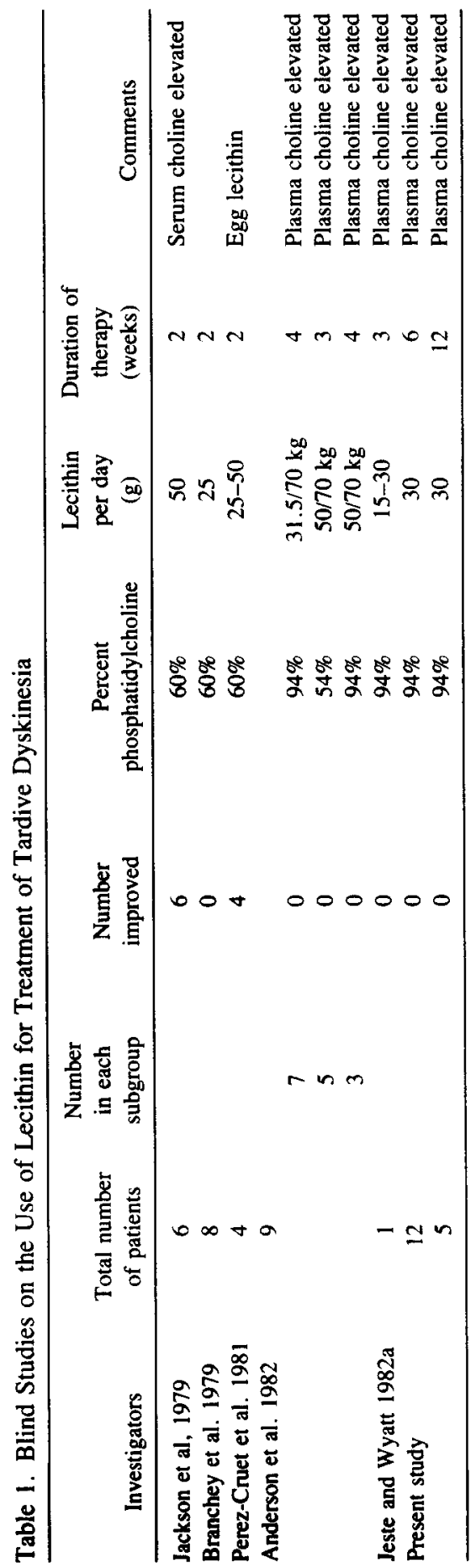



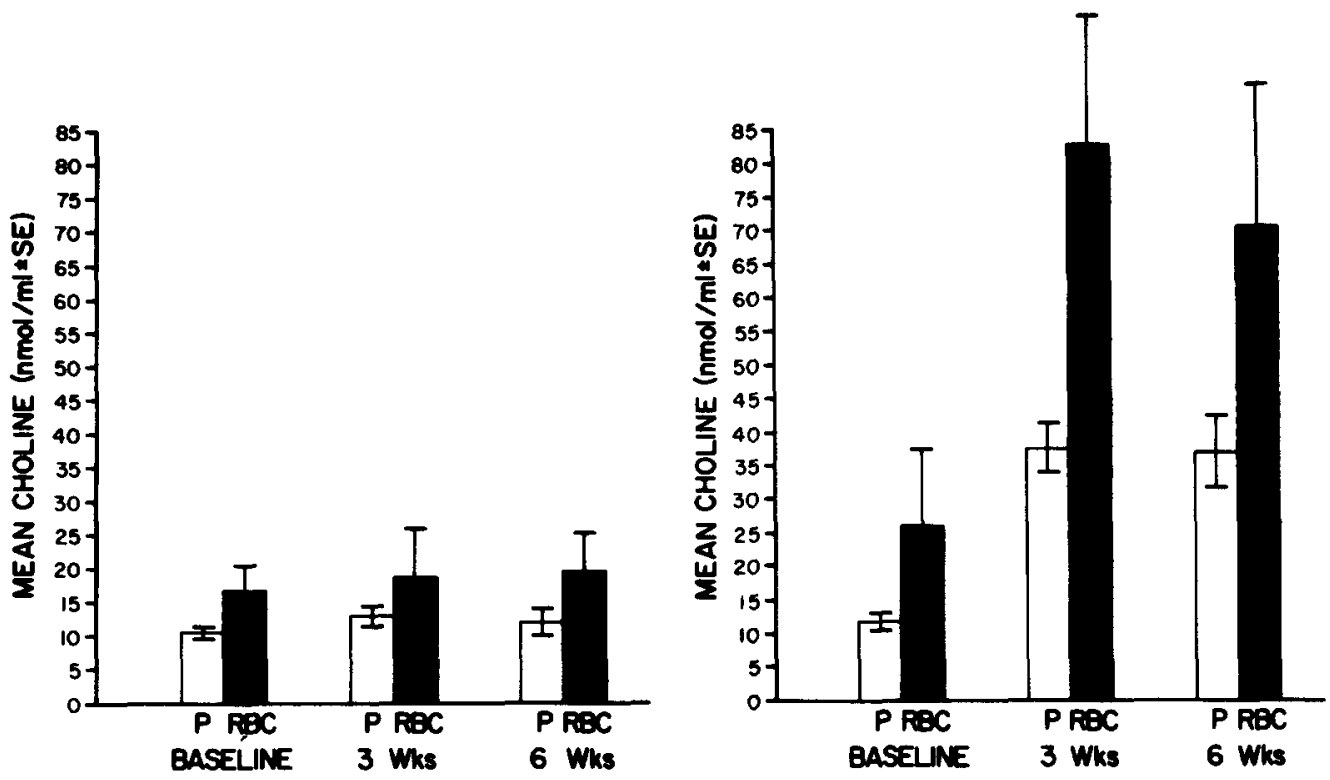

Figure 1. Effects of oral soya phosphatidylcholine on blood choline levels in patients with tardive dyskinesia (Lafayette Clinic study). A total of nine patients were given lecithin in their diet for 6 weeks. Plasma (P) and red blood cell (RBC) choline levels were determined under double blind placebo and lecithin conditions.
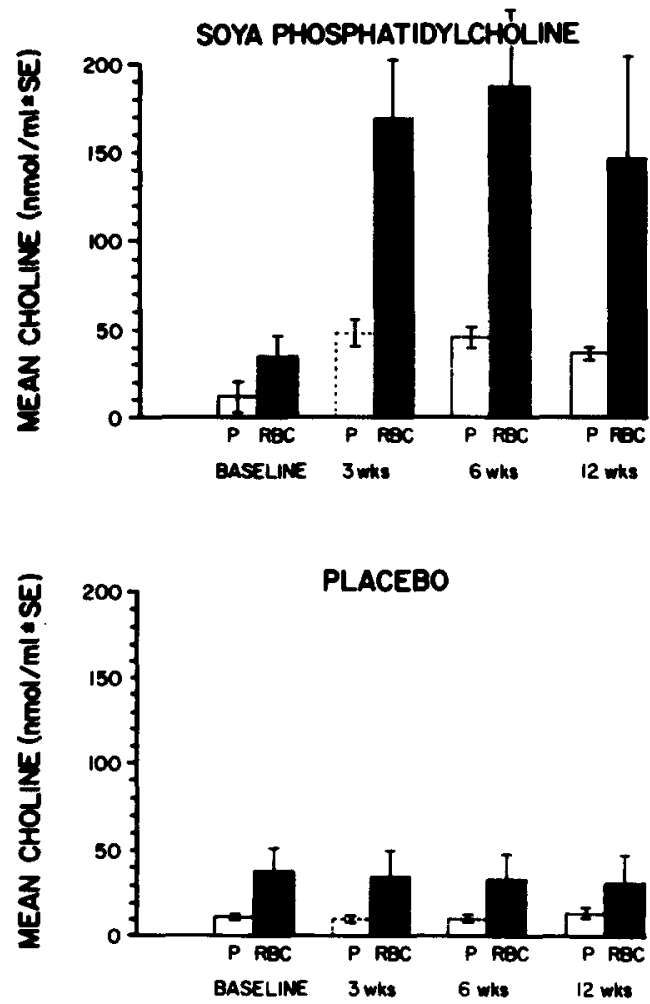

Figure 2. Effects of oral soya phosphatidylcholine on blood choline levels in patients with tardive dyskinesia (Ypsilanti Regional Psychiatric Hospital study). Five patients were given lecithin and another five were given placebo in their diet for 6 weeks; all were given the crossover treatment for 12 weeks. The choline levels were elevated from about 10 to $40 \mathrm{nmol} / \mathrm{ml}$ in plasma and from 40 to $150-180 \mathrm{nmol} / \mathrm{ml}$ in their red blood cells. 
Mean and SE of all of the measures were calculated and the data compared using Student's $t$-test (Snedecor 1956). Differences among the repeated observations in the same patients were analyzed for matched pairs (correlated $t$-test). Measures compared across patient groups were based on independent means (uncorrelated $t$-test).

Results

Phosphatidylcholine dramatically elevated plasma and red blood cell choline compared with placebo in both the LC and Ypsi patients, as shown in Figures 1 and 2. The increases are statistically significant $(p<0.05)$ and are greater in the Ypsi than in the LC group of patients. In view of the small number of patients from each institution, and in view of the similarity of the results, the clinical assessment data of both groups were pooled.

As can be seen in Figure 3 from the Physician's Global Rating, there was a slight psychiatric improvement after 3 weeks of lecithin compared with placebo, which was not true after 6 weeks. In contrast, the Nurse's Global Rating scale had no psychiatric improvement whatsoever. Interestingly, the Emergent Symptoms Scale indicated that after 3 weeks of placebo the patients had fewer side effects than when given lecithin. However, lecithin treatment for 6 to 12 weeks did not increase the number of side effects

\section{COMBINED MEAN DATA OF YPSI AND LC CROSSOVERS}
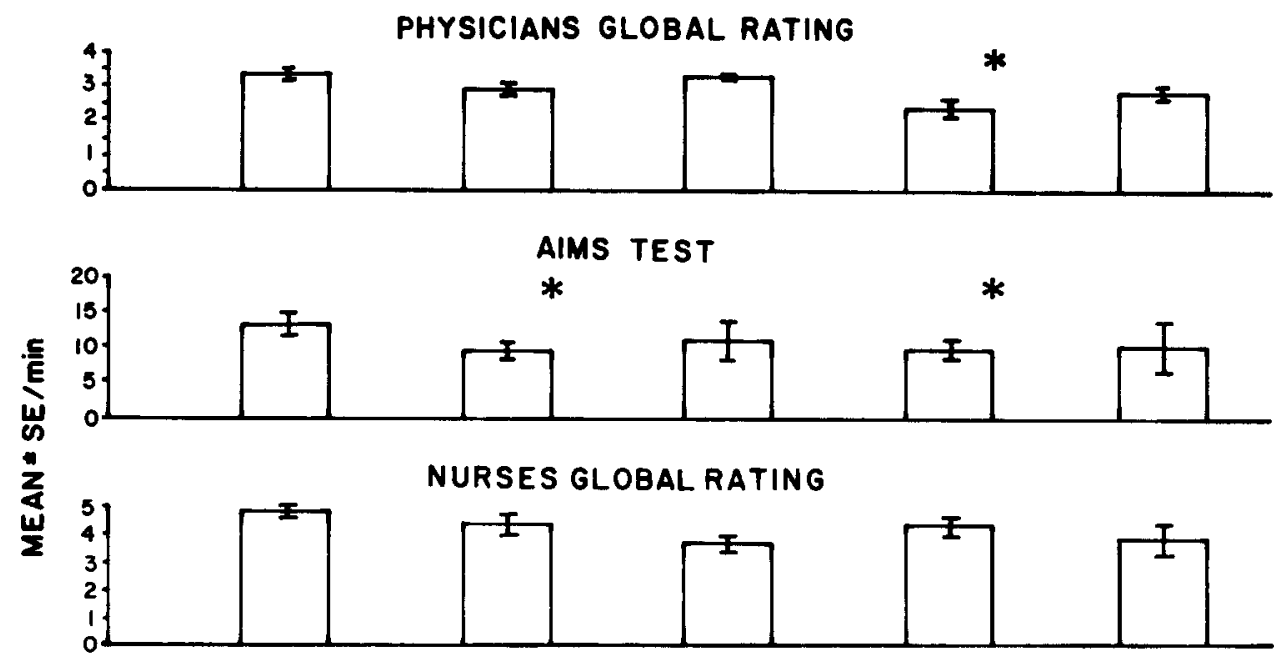

EMERGENT SYMPTOMS SCALE

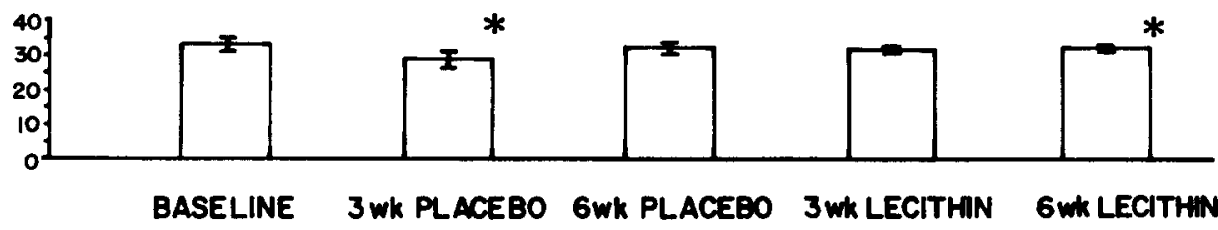

Figure 3. Combined mean data on the Physician's Global Rating, AIMS Test, Nurse's Global Rating, and Emergent Symptoms Scale. Each score represents the mean \pm SE of approximately 19 patients. ${ }^{*} p<0.05$ compared with baseline scores. 
compared with placebo. Insofar as motor movements were concerned, based on the Abnormal Involuntary Movement Scale, they seemed to be decreased after both placebo and lecithin at 3 weeks $(p<0.05)$, but not at 6 weeks of lecithin therapy.

When mouth movements were counted from observation of the videotapes under four conditions (quiet, mouth open, tongue out, and finger tapping), no consistent improvement was observed with either therapy (Figure 4). After 6 weeks of lecithin, the patient's mouthing movements (mouth open, tongue out) actually appeared somewhat worse $(p<0.05)$.

\section{Discussion}

Results of this study are very clear. Oral phosphatidylcholine therapy raised plasma and red blood cell choline levels to at least $300 \%$ above baseline at both 3 and 6 weeks. In contrast, placebo therapy had no effect on blood choline levels. In spite of a marked increase in blood choline, phosphatidylcholine therapy did not improve any of the signs and symptoms of TD compared with placebo. Blood choline levels were considerably greater in the Ypsi inpatients than in the LC inpatients and outpatients $(p<0.05)$. This finding suggests that compliance in the LC patients was lower. However, neither hospital group of patients showed any significant improvements so the clinical data were pooled.

\section{COMBINED MEAN DATA OF MOUTH MOVEMENTS (YPSI AND LC CROSSOVERS)}
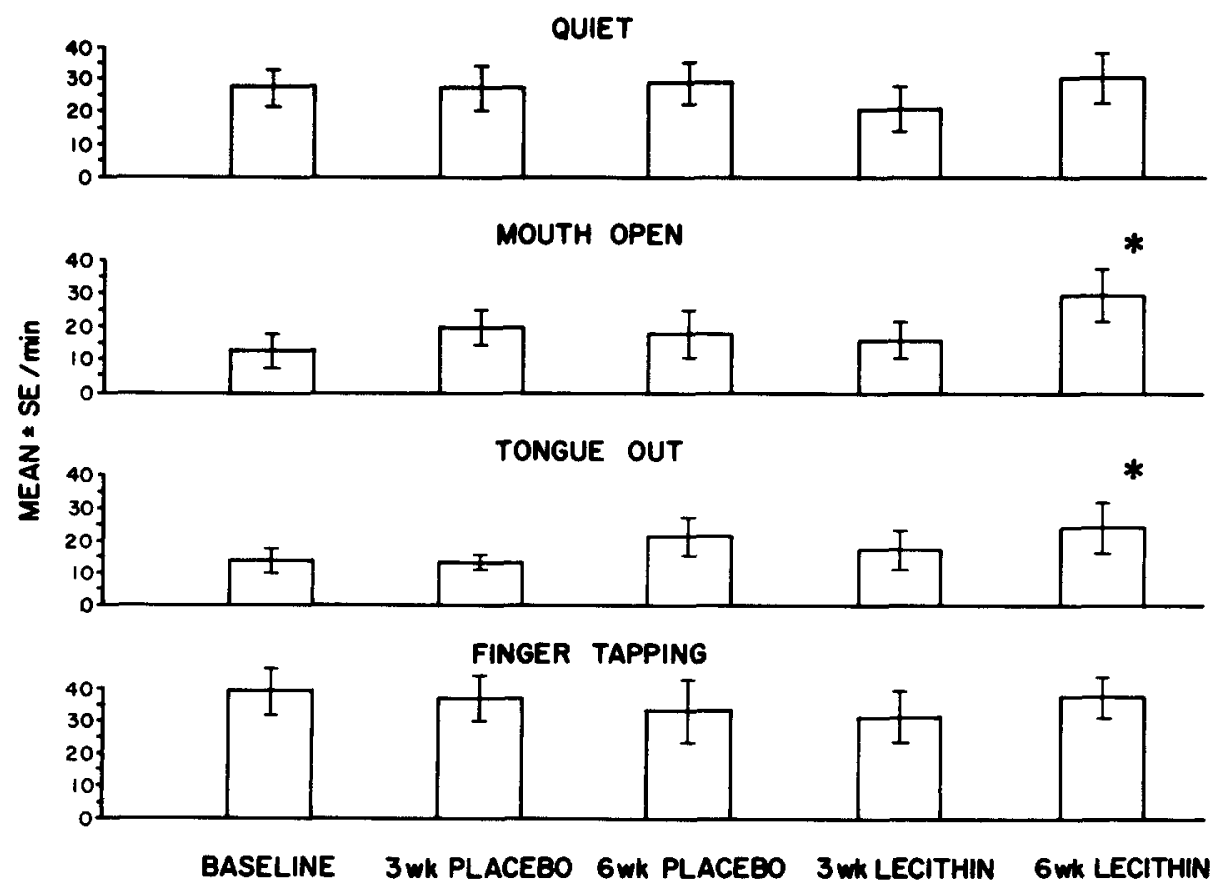

Figure 4. Combined mean data on movements as measured from closed circuit television recordings. Means \pm SE or mouth movements per minute were obtained for 19 patients. $p<0.05$ compared with baseline scores. 
When the results of the present study are combined with those of other blind studies on the treatment of TD with lecithin, the ratio of number of lecithin-treated patients who improved to total number of lecithin-treated patients is $10: 45$, i.e., $22 \%$.

It is clear that lecithin is not a reliable treatment for TD. Speculation as to why this is so involves the following considerations. Neither Jope (1982) nor Domino et al. (1983) were able to confirm the findings of Hirsch and Wurtman (1978) that in rodents dietary lecithin elevates brain levels of $\mathrm{ACh}$; Wurtman and associates, however, were able to confirm that finding (Magil et al. 1981). The ability of peripherally administered choline itself to elevate brain $\mathrm{ACh}$ is controversial (Brunello et al. 1982). Even if brain ACh is increased after precursor loading, there is no guarantee that central cholinergic neurotransmission will also be increased. Some evidence of increased neurotransmission comes from the work of Wurtman and associates and of Haubrich and associates. These investigators reported that peripherally administered choline increased brain ACh (Cohen and Wurtman 1975; Haubrich et al. 1975) and that such treatment could also cause chemical changes in certain neurons (striatal dopaminergic neurons) that receive input from cholinergic neurons; indirect pharmacological evidence indicated that the changes in the dopaminergic neurons were due to increased release of ACh from presynaptic terminals (Ulus and Wurtman 1976; Haubrich and Pfleuger 1979). However, Eckernas et al. (1977) and Brunello et al. (1982) found no indication of increased turnover of brain $\mathrm{ACh}$ when plasma choline levels were elevated after infusions of labeled choline. In humans, drugs affecting cholinergic transmission produce electroencephalographic changes (Itil and Fink 1968; Pfefferbaum et al. 1979) but no significant changes have been observed after lecithin (Rabin et al. 1983; Volavka et al. 1983). In four normal volunteers, lecithin did not affect secretion of hormones known to be under cholinergic control (Rabin et al. 1983).

In view of the foregoing, it seems reasonable to ascribe the negative results of the present study to the likelihood either that lecithin did not enhance central cholinergic activity or that central cholinergic activity is not involved in the mechanism of tardive dyskinesia. It is of interest that the use of lecithin for the treatment of Alzheimer's disease, which is unequivocally associated with central cholinergic deficits, also has produced predominantly negative results (Johns et al. 1983). Branconnier et al. (1984) have suggested that one possible explanation for the negative findings with oral lecithin therapy in Alzheimer's disease may be a lack of adequate plasma choline concentrations as based upon their dose-response analysis of plasma choline to oral lecithin. Clearly the plasma choline levels in the TD patients in this study were markedly elevated and thus this suggestion is not applicable.

The authors would like to acknowledge the assistance of the following individuals who helped make this project possible. Lafayette Clinic: Dr. Norma Josef, Dr. Aurelio Ortiz, Mr. Gene Dembicki, and Ms. Diane Ruffing. Ypsilanti Regional Psychiatric Hospital: Dr. Hewes, Mrs. E. Carros, R.N., Ms. A. Kovacs, R.N., and Ms. Bonnie Hoover-Jansen. Walter Reuther Hospital: Dr. Wexler. University of Michigan: Mr. Christian Ballast.

\section{References}

Alphs LD, Davis JM (1983): Cholinergic treatments for tardive dyskinesia. Mod Probl Pharmacopsychiatry 21:168-186.

Anderson BG, Reker D, Ristich M, Friedman E, Banay-Schwartz M, Volavka J (1982): Lecithin treatment of tardive dyskinesia-a progress report. Psychopharmacol Bull 18:87-88.

Branchey MH, Branchey LB, Bark NM, Richardson MA (1979): Lecithin in the treatment of tardive dyskinesia. Commun Psychopharmacol 3:303-307. 
Branconnier RJ, Dessain EC, Cole JO, McNiff-Langille ME (1984): An analysis of dose-response of plasma choline to oral lecithin. Biol Psychiatry 19:765-770.

Brunello N, Cheney DL, Costa E (1982): Increase in exogenous choline fails to elevate the content or turnover rate of cortical, striatal, or hippocampal acetylcholine. J Neurochem 38:1160-1163.

Buchanan DN, Fucek FR, Domino EF (1980): Paired ion high performance liquid chromatographic assay for plasma choline. $J$ Chromatogr 181:329-336.

Cohen E, Wurtman RJ (1975): Brain acetylcholine: Increase after systemic choline administration. Life Sci 16:1095-1102.

Domino EF, Mathews BN, Tait SK, Ortiz A (1983): Effects of oral phosphatidylcholine on mouse brain choline and acetylcholine. Arch Internat Pharmacodyn Ther 265:49-54.

Eckernas S-A, Sahlstrom L, Aquilonius S-M (1977): In vivo turnover rate of acetylcholine in rat brain parts at elevated steady-state concentration of plasma choline. Acta Physiol Scand 101:404-410.

Guy W (1976): ECDEU Assessment Manual for Psychopharmacology. DHEW Publ No (ADM) 76-338. Washington, DC: Government Printing Office.

Haubrich DR, Pfleuger AB (1979): Choline administration: Central effect mediated by stimulation of acetylcholine synthesis. Life Sci 24:1083-1090.

Haubrich DR, Wang PFL, Clody DE, Wedeking PW (1975): Increase in rat brain acetylcholine induced by choline and deanol. Life Sci 17:975-980.

Hirsch MJ, Wurtman RJ (1978): Lecithin consumption increases acetylcholine concentrations in rat brain and adrenal gland. Science 202:223-225.

Itil TM, Fink M (1968): EEG and behavioral aspects of the interaction of anticholinergic hallucinogens with centrally active compounds. In Bradley PB, Fink M (eds), Anticholinergic Drugs, Progress in Brain Research, Vol 8. Amsterdam: Elsevier.

Jackson IV, Nuttall EA, Ibe O, Perez-Cruet J (1979): Treatment of tardive dyskinesia with lecithin. Am J Psychiatry 136:1458-1460.

Jenden DJ, Hanin I, Lamb SI (1968): Gas chromatographic microestimation of acetylcholine and related compounds. Anal Chem 40:125-128.

Jeste DV, Wyatt RJ (1982a): Understanding And Treating Tardive Dyskinesia. New York: Guilford Press.

Jeste DV, Wyatt RJ (1982b): Therapeutic strategies against tardive dyskinesia-two decades of experience. Arch Gen Psychiatry 39:803-816.

Johns CA, Greenwald BS, Mohs RC, Davis KL (1983): The cholinergic treatment strategy in aging and senile dementia. Psychopharmacol Bull 19:185-197.

Jope RS (1982): Effects of phosphatidylcholine administration to rats on choline in blood and choline and acetylcholine in brain. $J$ Pharmacol Exp Ther 220:322-328.

Klawans HL (1973): The pharmacology of tardive dyskinesias. Am J Psychiatry 130:82-86.

Kosh JW, Smith MB, Sorrell JW, Freeman JJ (1979): Improvements in the gas chromatographic analysis of acetylcholine and choline. J Chromatogr 163:206-211.

Magil SG, Zeisel SH, Wurtman RJ (1981): Effects of ingesting soy or egg lecithins on serum choline, brain choline and brain acetylcholine. $J$ Nutr 111:166-170.

Perez-Cruet J, Menendez I, Alvarez-Ghersi J, et al. (1981): Double-blind study of lecithin in the treatment of persistent tardive dyskinesia. Bol Asoc Med PR 73:531-537.

Pfefferbaum A, Davis KL, Coulter CL, Mohs RC, Koppel BS (1979): Electrophysiological effects of physostigmine in humans. In Davis KL, Berger PA (eds), Brain Acetylcholine and Neuropsychiatric Disease. New York: Plenum Press, pp 345-360.

Rabin PL, Gooch BR, Teschan PE, Schmidt DE, Island DP, Rabin D (1983): Effects of dietary lecithin on hormonal and neurobehavioral profiles in normal subjects. J Clin Psychiatry 44:136-138.

Snedecor GW (1956): Statistical Methods. Ames: Iowa State University Press.

Ulus IH, Wurtman RJ (1976): Choline administration: Activation of tyrosine hydroxylase in dopaminergic neurons of rat brain. Science 194:1060-1061.

Volavka J, Lifshitz K, Friedman E, Sherman KA, Banay-Schwartz M (1983): Effects of lecithin on EEG and blood levels of choline. Biol Psychiatry 18:1175-1179. 